\title{
Antarctic Diplomacy in a Time of Pandemic
}

\author{
Klaus Dodds \\ Department of Geography, Royal Holloway, University of London, \\ Egham, UK \\ K.Dodds@rhul.ac.uk \\ Alan D. Hemmings \\ Gateway Antarctica Centre for Antarctic Studies and Research, \\ University of Canterbury, Christchurch, New Zealand \\ alandhemmings@xtra.co.nz
}

Received: 17 June 2020; revised: 31 August 2020; accepted: 21 September 2020

\section{Summary}

In the reporting about CoviD-19 diplomacy, Antarctica has functioned as the exceptional - the only continent, thus far, not to record a single case of covid-19, although cases were reported on Antarctic tourism vessels in the northern Antarctic Peninsula. For six decades, Antarctic governance has been an experiment in global democracy and diplomacy. Under the auspices of the Antarctic Treaty (1959) and associated legal instruments, all Consultative Parties from Argentina to Ukraine have the same fundamental rights to be engaged with the business of managing Antarctica. This essay speculates on ramifications of the pandemic for Antarctic governance and diplomacy. What are the implications when geographical distancing is joined by new forms of social distancing? Does the model of Antarctic governance and diplomacy still work? One possible future scenario is that conservation enforcement suffers because relevant parties refuse to accept the presence of others and weaponise public health to prevent public scrutiny.

\section{Keywords}

Antarctica - Antarctic Treaty - international relations - governance - diplomacy COVID-19 


\section{Introduction}

In the midst of all the reporting about covid-19 diplomacy, Antarctica has functioned (yet again) as the exceptional. At the time of this writing, it is the only continent to have not recorded a single case of CoviD-19, although cases have been reported from Antarctic Peninsula tourism vessels. ${ }^{1}$ But these reports have failed to recognise that the Antarctic's diplomatic and geopolitical hinterlands have been impacted.

For six decades, Antarctic governance has been an experiment in global democracy and diplomacy. Under the Antarctic Treaty (1959) and associated legal instruments, Consultative Parties from Argentina to Ukraine have the same fundamental rights to be engaged with the business of managing Antarctica. ${ }^{2}$ Working with the United States, China and Russia, the workings of the Antarctic Treaty provide evidence for how diplomacy and governance align with national self-interest and international common good. Governance is by consensus - if any one Consultative Party objects to a proposal, then it fails to progress. While generating complaints about sclerotic governance on timesensitive issues such as fisheries protection and in relation to environmental protection, ${ }^{3}$ the virtue is that 'consensus' Antarctic-style ensures general ownership of decisions - even if these are harder to achieve. Critically, consensus decision-making was essential to the agreement of claimants to the Antarctic Treaty in the first place, and (as with the UN Security Council Permanent Five) gaining agreement to change seems unlikely.

But does this depend on face-to-face encounters, regular meetings and a shared sense of the international common good? Previous work has drawn attention to the performative and embodied nature of diplomacy, with conferences and summitry framed as performative acts of environmental and public health governmentality. ${ }^{4}$ Summits provide, for example, opportunities for parties and delegations to perform, exhibit and communicate their authority, agendas and police what counts as legitimate and responsible conduct. ${ }^{5}$ More than any other 'terrestrial' area of the earth, Antarctic governance and diplomacy is conducted at a distance. Consultative Parties do not meet in Antarctica but in the cities of the participating states. What happens in Antarctica is the on-site or at-sea monitoring and observation and the compliance checking of

1 High levels on one of these vessels (Greg Mortimer) were reported by Ing et al. 2020 .

2 Dodds 2012.

3 See the call for majority decision-making in an editorial in Nature 2018.

4 Death 2011.

5 There already are suggestions that some states are 'taking advantage' of the pandemic to advance their interests; see Feiger and Wilson 2020. 
activities such as fishing, tourism and science. These need to be observed by other treaty parties as part of the confidence and trust-building framework that is implicit in the Antarctic Treaty System (ATS).

This commentary speculates on the ramifications of the pandemic for Antarctic governance and diplomacy. What are the implications when geographical distancing is joined by new forms of social distancing? Does the model of Antarctic governance and diplomacy still work? And what happens to a model of governance underpinned by the legitimacy of science (with accompanying systems of observation and monitoring) when scientific activity in Antarctica is disrupted by the pandemic, and capacity to convene scientific and other technical advisory groups is constrained? Major operators such as British Antarctic Survey announced in the summer of 2020 that their plans for the new summer season of 2020-2021 would be severely impacted — deep field science postponed, limited co-operation with international partners and delays in construction. ${ }^{6}$ More disturbing is what might happen to the monitoring of fishing activity in the Southern Ocean - What happens when that is not possible because states disagree about public health standards? One scenario for the future is that conservation enforcement suffers because relevant parties refuse to accept the presence of others and weaponise public health to prevent public scrutiny.

\section{Antarctic Diplomacy and Governance in a Time of Pandemic}

The mechanisms of Antarctic governance, even pre-pandemic, are showing signs of wear and tear, perhaps a hollowing out. ${ }^{7}$ No new Antarctic instruments have been adopted since the 1991 Protocol, and none are under negotiation. Tourism is managed in consultation with a still largely Western-orientated industry group, the International Association of Antarctica Tour Operators, but with Chinese tourism companies now rapidly emerging. Procedurally, the ATs has functioned as an in-person regime, where face-to-face meetings and even 'corridor talk' are prized by diplomatic representatives at the annual meetings - decision-making is done at those events and, hence, it is perhaps not surprising. ${ }^{8}$ Decision-making by consensus also demands high levels of emotional as well as practical labour. ${ }^{9}$ Relationships are made and remade at

\footnotetext{
6 BBC News 2020.

7 Hemmings 2017 .

8 Jones and Clark 2006; Hodder 2015.

9 Constantinou 2006; Hodder 2015.
} 
the meetings. Every major decision will have been considered in the four treaty languages of English, French, Russian and Spanish. While intersessional work is conducted through electronic means, this is still largely restricted to technical matters. Antarctic governance has not embraced digital working technologies in relation to substantive matters in a way that other international regimes and intergovernmental forums, such as the Arctic Council, have.

In Stephen Krasner's definition of an 'international regime', ${ }^{10}$ the text of the 1959 Antarctic Treaty, ${ }^{11}$ carried with it an assemblage of norms (e.g., all signatories would be treated equally), principles (e.g., states would share information freely and conduct scientific activity in the main), rules (e.g., territorial sovereignty was effectively suspended for the duration of the treaty, four recognised treaty languages) and decision-making procedures (meetings — later termed Antarctic Treaty Consultative Meetings (АтСM s), decision-making by consensus). The Treaty mandated face-to-face meetings and noted that the parties planned to meet next in Australia:

for the purpose of exchanging information, consulting together on matters of common interest pertaining to Antarctica, and formulating and considering, and recommending to their Governments, measures in furtherance of the principles and objectives of the Treaty. ${ }^{12}$

The end result was a treaty, adopted by twelve states, which subsequently attracted more - including, in the 1980s, Global South giants Brazil, China and India. Antarctic governance over the past 60 years has expanded into a system, the ATs, with the addition of other legal instruments such as the Convention on the Conservation of Antarctic Marine Living Resources (CCAMLR) and the Protocol on Environment Protection to the Antarctic Treaty (Protocol). Both ATCMS and CCAMLR meetings are annual affairs. ATCMs rotate around the membership and thus can occur anywhere in the world; CCAMLR Commission meetings are always held in Hobart. Over the decades, the 'bordering' mechanisms of Antarctic governance have been altered by a variety of factors including an expanding membership, a growing presence of third parties as observers, so-called 'gateway state' activities and intensifying global scrutiny of how the Polar South has and is managed..$^{13}$ In the 1970 and 1980 s, resource

\footnotetext{
$10 \quad$ Krasner 1982.

11 Text available in Saul and Stephens 2015.

12 Article IX of the 1959 Antarctic Treaty.

13 Nicklin 2020. There are a number of gateway states, including: Argentina, Australia, Chile, New Zealand and South Africa. The British overseas territory, the Falkland Islands, acts as a gateway to Antarctica as well.
} 
exploitation, including fishing, whaling and even mineral resources, provoked a radical shift in global diplomatic and political attention. The UN General Assembly considered, on an annual basis, the so-called 'Question of Antarctica' from the 198 os onwards. There was an annual ritual to Antarctic diplomacy with Australia being asked to represent the interests of the Antarctic Treaty parties in the UN - which included defending apartheid South Africa's continued membership. ${ }^{14}$

Between the late 196os and early 1990s, there was an appetite, even necessity, for change and innovation within the ATs. New instruments were developed in response to perceived resource issues. Membership increased from the original 12 of the Treaty to 30 states and the European Union acquiring decision-making status, with 29 other states acceding to one or more of the instruments. Despite conflict between the United Kingdom and Argentina in 1982 over the Falklands/Malvinas, the Antarctic was not caught up in any direct antagonism..$^{15}$ Abandonment of a completed minerals convention did not derail Antarctic governance in the late 1980s, despite fears that it might. Negotiation of a new Protocol, banning mineral exploitation under Article 7 , was completed quickly (even if entry into force took another seven years). Even the more recent controversy over the Ross Sea marine protected area, while protracted and potentially divisive between fishing and conservationminded Member States, did not lead to permanent governance fractures. ${ }^{16}$

The traditional function of Antarctic diplomacy has been to maintain norms, principles and rules in situ. Expert meetings and the annual AтсM s are textbook examples of 'summit theatre.' ${ }^{17}$ The host of the ATсM has ten days to showcase its Antarctic credentials and manage through formal and informal event management the business of the Treaty. There is also an atmospheric geography to the conference - delegates congregate around large tables with their respective national flags on display. There are 'repertories' of summit behaviour to be followed, reinforced in person. ${ }^{18}$ Side meetings are held in breakout spaces, and some parties have had a long history of collaborating closely with another, notably the United States, the United Kingdom, Norway, Australia and New Zealand.

The pre-pandemic workings of Antarctic governance and diplomacy favoured the original signatories. The terms and conditions of the Antarctic

\footnotetext{
14 Hemmings 2014.

15 It was not, however, without consequences; see Dodds and Hemmings 2013.

16 Brooks et al. 2020.

17 Shimazu 2014.

18 McConnell 2018.
} 
Treaty were established in 1959 and the reluctance to embrace digital working is in large part due to the great weight given to personal networking and faceto-face working. Consensus was understood to be something that was securable in person. Crises in the past were said to have been averted by personal diplomacy even if political leaders such as Michel Rocard of France and Bob Hawke of Australia were blamed at the time for undermining the previously agreed minerals convention by those actors who still favoured that instrument. ${ }^{19}$

\section{Options for Change? The Implications for Antarctic Diplomacy and Governance}

At the time of this writing, there have been no cases of Covid-19 at any Antarctic station. ${ }^{20}$ With rigorous preventative measures now being drawn up for the reduced 2020/2021 operational season, as with the Spanish flu of 1918-1919, Antarctica may entirely escape infection. Towards the end of the 2019/2020 season, once it became apparent that the world was dealing with a pandemic, national programmes began to make contingency plans not only to safely bring back Antarctic personnel but also to revise plans for the next summer season, October 2020-March 2021. ${ }^{21}$ The return of employees working in Antarctica proved complex given geography and border closures, airport restrictions and quarantine requirements in polar gateway ports in Argentina, Chile, South Africa, Australia, New Zealand, the Falkland Islands and elsewhere. So, the first operational impact of the pandemic was in relation to scientific and support staffs going to and return from Antarctica.

Away from Antarctica, the pandemic wrecked the scheduling of Antarctic governance. ${ }^{22}$ The annual ATCM due to be held in Finland in May 2020 was cancelled. The CCAMLR Commission meeting due in October is in doubt, and some of the intersessional advisory group meetings that ordinarily feed into it have already been cancelled. Because the Aтсм was cancelled, the Committee on Environmental Protection, which would have provided advice on what might be required to secure environmental values, could not meet.

Antarctic diplomacy and governance have a series of issues and problematics that have been exposed by the pandemic.

\footnotetext{
19 Press 2016.

20 Christchurch Antarctic Office 2020.

21 Hemmings and Frame 2020.

22 Hemmings 2020a.
} 


\subsection{Conducting Meetings}

There is a problem with meetings and how one conducts them. Discussions are currently under way about options for conducting the 2020 CCAMLR Commission meeting virtually, addressing a reduced agenda progressed through rolling online sessions of two to three hours in duration. How to deal with time zones, whether all four Treaty languages can be used for the usual simultaneous translation remain to be determined. States have, globally, viewed fishing activities as an essential activity through the pandemic, and the expectation is that the $2020 / 2021$ season will see near normal levels of marine harvesting. This has reinforced the need for the CCAMLR Commission to be able to assign catch allocations through its virtual arrangements. Operational questions, such as whether CCAMLR's scheme of inspection at sea and the placement of observers aboard vessels are feasible, remain to be determined. ${ }^{23}$

The next ATCM is scheduled for 2021 in France, probably in the second half although dates are not confirmed. If it proves impossible to convene the ATCM in person, another virtual meeting (assuming that is the CCAMLR outcome) may be necessary. A theoretical and obviously contingent alternative to a virtual meeting might be a meeting elsewhere (perhaps New York,), where all participating states already have high-level permanent diplomatic representatives, thus avoiding further diplomatic travel.

A third option, if pandemic conditions ease, might be to host ATCM and CCAM LR Commission meetings in their usual locations but make them shorter and reduce agendas and delegates. Conceivably, participation might be limited at Expert and Observer Groups (science, non-governmental organisations and industry), with priority given to decision-making state delegations.

\subsection{Antarctic Consensus}

Assuming that remote/virtual meetings are possible and acceptable, problems of control remain for a system based on consensus. This is particularly so for CCAMLR because the Commission meeting in Hobart signs off on critical economic and geopolitical decisions about catch allocations each year, codified in legally binding Conservation Measures. As an ecosystem-based fisheries management system, scientific advice plays a crucial role in informing the balance between conservation and exploitation. Each year, CCAMLR delegates engage in 'horse-trading'. As recent Marine Protected Area negotiations have revealed, the relationship between scientific advice and policy decision-making is not necessarily straightforward. What we are likely witnessing is a moment of profound 'liminal geopolitics' as Fiona McConnell has noted with reference to

23 Personal communications from officials to second author, July 2020. 
the spaces of diplomatic life punctuated by political uncertainty and institutional contingency. ${ }^{24}$ The norms, rules and procedures of Antarctic diplomacy were specifically designed to constrain rapid change. Claimant states, semiclaimants and the remaining non-claimants have (historically) had little to no incentive to indulge in anything but institutional conservatism..$^{25}$

All of the above might not be tenable if public health is used to frustrate the monitoring of conservation measures. If there are fewer opportunities to intervene in person, then does it make it easier for consensus to be 'lost'?

\subsection{Infrastructure}

The pandemic is potentially a game changer, too. Antarctic infrastructure and scientific projects will be disrupted. Costs will rise as every station manager seeks to maintain a COVID-19-free working environment. National science providers will need to devise new strategies to evacuate and protect staff in the Antarctic and beyond. Antarctic tourism is likely to be affected for some time (recovering from the 2007-2008 global financial crisis took a decade) and authorities sensitive to risk through ship transit of their ports. It inevitably will have to grapple alongside polar science stakeholders with shared problems such as a new CoviD-19 outbreak. We might see added pressures to reduce tourism numbers (including attempts to dissuade the industry from sending large cruise ships to the region) and incentives to automate Antarctic science where possible. For claimant states, however, a national scientific presence has never been divorced from their security and sovereignty agendas.

New coalitions might become a great deal more interested in international and shared stations and there might be a splintering of public health-led coalitions - depending on pandemic conditions in consultative parties. ${ }^{26}$

\subsection{Gateways}

There are a small number of 'gateway states' that provide the final point of departure to Antarctica and the first arrival point from Antarctica. For example, in April 2020 the New Zealand Cabinet agreed that 'essential workers' included Antarctic personnel and could be legitimate exceptions to CoviD-19 border restrictions. ${ }^{27}$ The Cabinet also agreed to the maintenance of New Zealand's search and rescue obligations in the Ross Sea Sector. ${ }^{28}$

\footnotetext{
24 McConnell 2017.

25 Putnam 1988.

26 Hemmings 202ob.

27 New Zealand Government 2020a.

28 New Zealand Government 202ob.
} 
We may also see other complications arising from domestic policies in relation to quarantine, lockdown, public health strategies and border security. For gateway ports and cities such as Cape Town, Christchurch, Hobart, Punta Arenas and Ushuaia, polar science and tourism is a major income generator. For example, Hobart and Christchurch see US, French, Italian, South Korean, Chinese and Russian programmes - as well as their own - transiting these ports, and Ushuaia is the funnel for the majority of tourism in the Antarctic Peninsula. National governments to the north of these cities might find themselves in conflict with their southern constituencies who will be eager to work with foreign partners. ${ }^{29}$ They will not want their port and airport facilities to be out of bounds. And they will be hopeful that the polar tourism industry with over 50,00o visitors (in the 2019-2020 season and predominantly ship based) will return as soon as possible.

Gateway diplomacy has been a notable feature of Antarctic geopolitics since the 1990 s - with competition for polar tourism and international visitations. The State of Tasmania continues to encourage Chinese tourists and scientific personnel at the same time as the Australian federal government worries about the Chinese presence in what it calls the Australian Antarctic Territory.

\section{Antarctica and the Post-Pandemic International Order}

In terms of a post-pandemic prognosis, subtle and not so subtle demands for change are likely in Antarctic governance. The ATs was designed by the United States and its allies. ${ }^{30}$ If US leadership declines in Antarctic affairs, it might create opportunities for China to launch fresh proposals with others such as India and Russia to 'modernise' the ATs. Digital working, more regular decisionmaking outside of formal meetings, more treaty languages and more institutional backing for secretariats so that they can better liaise with UN agencies and issues, including the protection of biodiversity in areas beyond national jurisdiction, could be on the negotiating table. As non-claimants, India and China might otherwise conclude that the ATS will always remain a 'conservation club' for claimants and semi-claimants.

New members have joined, but the rules and procedures (and Treaty languages) were largely shaped by the original twelve parties. If you remove the 'political atmospherics' and the intimate diplomatic networks, does that create new spaces for China to re-establish a new working environment? The two

29 For example, Mayor and Antarctic Office in Star News 2020.

30 Hemmings 2020c. 
Antarctic Secretariats are weak, with decision-making powers confined to the CCAMLR Commission and ATCMs. Checks on state autonomy are modest and, despite fallacious speculation about the Treaty system necessarily being 'reviewed' in 2048, profound changes could be made within the system itself. China is just too important not be kept in the Antarctic club (and we could say the same for Russia and the United States). ${ }^{31}$

Antarctic governance in the Covid-19 era might bring a series of positives with it. A more rapid and responsive decision-making model, which is better attuned to the urgent realities of the Anthropocene, is very necessary. ${ }^{32}$ Antarctic science might be consolidated and shared amongst the networking of existing stations. There might be further effort to code-share logistics and planning of new initiatives on the ice. Tourism might turn away from the trend towards larger cruise ships and become smaller and more expedition in style.

The alternative scenario is infinitely more competitive, less co-operative and reconnected to systemic challenges such as US-Chinese rivalries and resource competition, with sometimes conflicting views on the priorities for management in the Southern Ocean being the most likely catalyst for disputation.

\section{Bibliography}

Brady, Anne-Marie. China as Great Polar Power (Cambridge: Cambridge University Press, 2017).

Bray, Daniel 'The Geopolitics of Antarctic Governance: Sovereignty and Strategic Denial in Australia's Antarctic Policy'. Australian Journal of International Affairs 70 (3) (2016), 256-274.

Brooks, Cassandra, Larry B. Crowder, Henrik Österblom and Aaron L. Strong. 'Reaching Consensus for Conserving the Global Commons: The Case of the Ross Sea, Antarctica'. Conservation Letters 2020; 13:e12676. D OI 10.1111/conl.12676.

Christchurch Antarctic Office. 'Update from Michelle Rogan-Finnemore, comNaP Executive Secretary'. 26 May 2020. https://www.christchurchnz.com/news/update -from-michelle-rogan-finnemore-comnap-executive-secretary.

'Christchurch Welcomes International Antarctic Workers'. Star News, 6 August 2020. https://www.odt.co.nz/star-news/star-christchurch/christchurch-welcomes-inter national-antarctic-workers.

Constantinou, Costas M. 'On Homo-Diplomacy'. Space and Culture 9 (4) (2006), 351-364.

31 Bray 2016; Brady 2017.

32 Stephens 2019. 
'Coronavirus Severely Restricts Antarctic Science.' BBC News, 7 August 2020. https:// www.bbc.co.uk/news/science-environment-53699681.

Death, Carl. 'Summit Theatre: Exemplary Governmentality and Environmental Diplomacy in Johannesburg and Copenhagen'. Environmental Politics 20 (1) (2011), 1-19.

Dodds, Klaus. The Antarctic: A Very Short Introduction (Oxford: Oxford University Press, 2012).

Dodds, Klaus and Alan D. Hemmings. 'Britain and the British Antarctic Territory in the Wider Geopolitics of the Antarctic and the Southern Ocean'. International Affairs 89 (6) (2013), 1429-1444.

Feiger, Leah and Mara Wilson. 'The Countries Taking Advantage of Antarctica during the Pandemic'. The Atlantic, 15 May 2020. https://www.theatlantic.com/ politics/archive/2020/05/antarctica-great-power-competition-australia-united -states-britain-russia-china-arctic/611674/.

Hemmings, Alan D. 'Re-justifying the Antarctic Treaty System for the 21st Century: Rights, Expectations and Global Equity'. In Polar Geopolitics? Knowledges, Resources and Legal Regimes, eds. Richard C. Powell and Klaus Dodds (Cheltenham: Edward Elgar, 2014), 55-73.

Hemmings, Alan D. 'The Hollowing of Antarctic Governance'. In Science and Geopolitics of the White World: Arctic-Antarctic-Himalaya, eds. Prem Shanker Goel, Rasik Ravindra and Sulagna Chattopadhyay (Cham: Springer, 2017), 17-31.

Hemmings, Alan D. 'Antarctic Governance in a Time of Coronavirus'. ANZSIL Perspective 13 (May 2O2Oa). http://anzsil.org.au/resources/ANZSIL\%2OPERSPECTIVE\%2O MAY\%2O2O2O\%2OFINAL_\%5B5\%5D.pdf.

Hemmings Alan D. 'International Antarctic Stations'. In Antarctic Resolution, ed. Giulia Foscari (Baden: Lars Müller, 2O2ob).

Hemmings, Alan D. 'The Philosophy of Law in the Antarctic'. In Philosophies of Polar Law, eds. Dawid Bunikowski and Alan D. Hemmings (London: Routledge, 2O2Oc), 13-29.

Hemmings, Alan D. and Bob Frame. 'Antarctica's Latest Challenge: Coronavirus' In Antarctic Resolution, ed. Giulia Foscari (Baden: Lars Müller, 2020).

Hodder, Jake. 'Conferencing the International at the World Pacifist Meeting, 1949'. Political Geography 49 (2015), 40-50.

Ing, Alvin J., Christine Cocks and Jeffery Peter Green. 'CoviD-19: In the Footsteps of Ernest Shackleton'. Thorax, 27 May 2020. DOI 10.1136/thoraxjnl-2020-215091.

Jones, Alun and Julian Clark. 'Mundane Diplomacies for the Practice of European Geopolitics'. Geoforum 62 (2015), 1-12.

Krasner, Stephen D. 'Structural Causes and Regime Consequences: Regimes as Intervening Variables'. International Organization 36 (2) (1982), 185-205.

McConnell, Fiona. 'Liminal Geopolitics: The Subjectivity and Spatiality of Diplomacy at the Margins'. Transactions of the Institute of British Geographers 42 (1) (2017), 139-152. 
McConnell, Fiona. 'Performing Diplomatic Decorum: Repertoires of "Appropriate" Behaviour in the Margins of International Diplomacy'. International Political Sociology 12 (2018), 362-381.

Nature. 'Editorial. Reform the Antarctic Treaty'. Nature $55^{8}$ (2018), 161. Doi: 10.1038/ d41586-018-05368-7. https://www.nature.com/articles/d41586-o18-o5368-7.

New Zealand Government. 'Covid-19 Antarctic Issues: Providing Emergency and Essential Support to Antarctic Stations through New Zealand'. Cabinet Minute CAB-2O-MIN-o13O, 3 April $2020 a$.

New Zealand Government. 'CoviD-19 Border Restriction Exceptions for Essential Workers and Others'. Cabinet Paper aqczaf39m, undated, released 12 June 202ob.

Nicklin, Germana. 'The Implied Border Mechanisms of Antarctica: Arguing the Case for an Antarctic Borderscape'. Borderlands 19 (1) (2020), 27-61.

Press, Anthony. 'Antarctica: The Madrid Protocol 25 Years on'. Australian Outlook, 5 October 2016.

Putnam, Robert D. 'Diplomacy and Domestic Politics: The Logic of Two-Level Games'. International Organization 42 (3) (1988), 427-46o.

Saul, Ben and Tim Stephens, eds. Antarctica in International Law (Oxford: Hart, 2015).

Shimazu, Naoko. 'Diplomacy as Theatre: Staging the Bandung Conference of 1955'. Modern Asian Studies 48 (1) (2014), 225-252.

Stephens, Tim. 'Governing the Antarctic in the Anthropocene'. In Anthropocene Antarctica: Perspectives from the Humanities, Law and Social Sciences, eds. Elizabeth Leane and Jeffrey McGee (London: Routledge, 2019), 17-32.

\section{Klaus Dodds}

is Professor of Geopolitics at Royal Holloway University of London, and a Fellow of the Academy of Social Sciences. He is an Honorary Fellow of the British Antarctic Survey, Trustee of the Royal Geographical Society, and Editor-in-Chief of Territory, Politics and Governance. He is Co-Editor (with Chih Yuan Woon) of 'Observing' the Arctic: Asia in the Arctic Council and Beyond (Edward Elgar 2020).

\section{Alan D. Hemmings}

is Adjunct Associate Professor at the Gateway Antarctica Centre for Antarctic Studies and Research at the University of Canterbury in Christchurch, New Zealand. His research and writing focusses on the governance of Antarctica, and the manifestations and influence of nationalism and territoriality in the contemporary geopolitics of the region. He is the co-editor of a number of polar volumes, most recently as Co-Editor (with Dawid Bunikowski) of Philosophies of Polar Law (Routledge 2020). 